\title{
Cardiovascular Risk Profile in Health Cadres in Jatinangor, West Java
}

\author{
Badai Bhatara Tiksnadi, ${ }^{1}$ Rien Afrianti, ${ }^{1}$ Yulia Sofiatin, ${ }^{2}$ Arif Ridha, ${ }^{1}$ Faris Yuflih Fihaya, ${ }^{3}$ \\ Rully M. A. Roesli, ${ }^{4}$ Muhammad Rizki Akbar ${ }^{1}$ \\ ${ }^{1}$ Departement of Cardiology and Vascular Medicine Faculty of Medicine Universitas Padjadjaran \\ Bandung Indonesia, ${ }^{2}$ Departement of Public Health Faculty of Medicine Universitas Padjadjaran \\ Bandung, Indonesia, ${ }^{3}$ Faculty of Medicine Universitas Padjadjaran Indonesia, ${ }^{4}$ Departement of \\ Internal Medicine Faculty of Medicine Universitas Padjadjaran Bandung, Indonesia
}

\section{Abstract}

Background: Cardiovascular disease has very high morbidity and mortality, therefore, prevention of this disease becomes a national priority in the health programs. Health cadres, as an agent in community primary prevention, should have a good health condition. This study aimed to describe the cardiovascular risk profile in health cadresin Jatinangor, West Java.

Methods: This was a cross-sectional study, conducted in Cilayung Village, Jatinangor, in September 2018. Consecutive sampling was performed on 20 health cadres aged 25 - 64 years old who did not have previous cardiovascular events such as coronary heart disease or stroke. Clinical data were collected consisting of blood pressure, body mass index (BMI), random blood glucose, history of diabetes mellitus, physical activity and active smoking habits. Cardiovascular risk was assessed using Jakarta cardiovascular scores and European Relative Risk Score.

Results: Only 17 of 20 health cadres fulfilled the inclusion criteria with a systolic and diastolic blood pressure of $133.5 \pm 27.8 \mathrm{mmHg}$ and $81.1 \pm 14.8 \mathrm{mmHg}$, respectively, and BMI of $27.4 \pm 5.3 \mathrm{~kg} / \mathrm{m} 2$.The risk of cardiovascular disease in healthy cadres was at low (47.1\%), moderate $(41.2 \%)$ and high risk $(11.7 \%)$. The average of the European Relative Risk score was $1.88 \pm 0.9$. BMI $>30$ has a $40 \%$ high risk of cardiovascular disease.

Conclusions: Most of the health cadres in Jatinangor, West Java have a low and moderate risk of cardiovascular disease, even though there is a small percentage that is at a high risk. The awareness for prevention and management programs for risk factors needs to be raised among health cadres.

Keywords: Cardiovascular, Health Cadre, Jatinangor, risk profile

\section{Introduction}

Cardiovascular disease, especially coronary heart disease (CHD), causes a global health problem, including in Indonesia. CHD is still the number one cause of death in the world. ${ }^{1}$ Cardiovascular disease has very high morbidity and mortality, and is the highest spending funds of the National Social Insurance Administration Organization, known as BPJS, in the last 4 years. Based on the results of Basic Health Research (Riset Kesehatan Dasar, Riskesdas) in 2013, the national prevalence of coronary heart disease is ranging from $0.5 \%$ to $1.5 \%{ }^{2}$ The CHD has not only an impact on mortality but also on morbidity and may thus limit the patients' quality of life.

The acute coronary heart disease and cardiocerebrovascular disease often occur suddenly and fatal, therefore, early detection of the risk of cardiovascular disease is needed. Through the detection of risk factors and estimating the level of risk, appropriate interventions and monitoring can be optimally given. Risk factors in the developing of CHD are divided into non-modifiable and modifiable factors. $^{3}$

The development of this very rapid incidence of CHD can be prevented by both primary and secondary preventive measures. Primary preventive includes prevention of CHD in patients with high risk; whereas

Correspondence: Badai Bhatara Tiksnadi, Departement of Cardiology and Vascular Medicine, Faculty of Medicine, Universitas Padjadjaran, Jalan Prof. Eijkman No.38, Bandung, West Java, Indonesia Email: tiksnadi_badai@yahoo.com 
secondary prevention is an effort to prevent recurrent CHD in patients who have previously suffered from CHD. Prevention efforts include minimizing all forms of risk factors. This preventive effort can reduce mortality by $50 \%$, while curative efforts can only reduce by $40 \%$. Modification of risk factors has been shown to reduce morbidity and mortality. ${ }^{4}$

Efforts to prevent cardiovascular disease in the last 10 years can be estimated by calculating current cardiovascular scores. The Jakarta Cardiovascular Score is a modification of the Framingham Score. The Jakarta Cardiovascular Score has a sensitivity of 77.9\% and a high specificity of $90 \%$. This score also provides a positive predictive value of $92.2 \%$ and a negative predictive value of $72.8 \% .^{5}$ The score is based on gender, age, blood pressure, smoking, diabetes, body mass index, and weekly physical activity.

Health cadres as a real manifestation of community participation in the health sector play an important role in helping to actualize community health development in the region. ${ }^{6}$ Health cadres are a group in a society that is expected to have the best knowledge about health. To carry out health promotion and primary prevention measures specifically regarding CHD in the community, good knowledge and understanding of CHD risk factors is needed, which can shape preventive attitudes and behaviors towards the disease. As best as we know, this was the first study aiming to describe the cardiovascular risk profile in health cadres, especially in Jatinangor sub-district, West Java based on Jakarta Cardiovascular Scores and European Relative Risk Score.

\section{Methods}

This was a cross-sectional study, conducted in Jatinangor Sub-district, Sumedang, West Java in September 2018. This study was approved by the Research Ethics Committee of Universitas Padjadjaran No. 1107/UN6.KEP/ EC/2018.

Health cadres were recruited by consecutive sampling (n20), all were female, aged 2465 years old. Only those who completed questionnaires were included. Clinical data weretaken, including blood pressure (digital tensiometer $\mathrm{ABN}-100$ ), body mass index (BMI), random blood glucose (digital blood glucose test Accu Chek Active), the history of Diabetes Mellitus, physical activity and active smoking habits. Data were further classified according to the Jakarta Cardiovascular Score and European Relative Risk Score referred to as SCORE. 5,7

The distribution of data on gender, age, blood pressure, body mass index, smoking history, diabetes, and physical activity were presented in table forms and graphs, using IBM SPSS Statistics version 20.

\section{Results}

Of 20 health cadres, only 17 had met the inclusion criteria whereas the three subjects were excluded due to incomplete data. Clinical data characteristics of the health cadres were presented in Table 1.

In this study, all health cadres were women with an average age of $44 \pm 8.31$ years. The average of systolic and diastolic blood pressure were $133.53 \pm 27.88 \mathrm{mmHg}$ and $81.19 \pm 14.87$ $\mathrm{mmHg}$, respectively, and the body mass index was $27.42 \pm 5.37 \mathrm{~kg} / \mathrm{m}^{2}$.

Most of them never smoked (94.1\%). Diabetes mellitus was detected in 2 cadres $(11.8 \%)$, and all cadres had medium physical activity (Table 2). The cardiovascular risk in all women's health cadres was low (47.1\%), moderate $(41.2 \%)$ and high $(11.7 \%)$, respectively.

According to Jakarta Cardiovascular Score, the risk of cardiovascular disease was low

Table 1 Characteristics of Health Cadres Recruited from Jatinangor, West Java

\begin{tabular}{lccc}
\hline \multicolumn{1}{c}{ Variable } & Mean (SD) & Median & Range \\
\hline Age (years) & $44.88(8.31)$ & 45 & $28-62$ \\
Blood Pressure (mmHg) & & & \\
$\quad$ Systole & $133.53(27.88)$ & 133 & $92-186$ \\
$\quad$ Diastole & $81.19(14.87)$ & 79 & $60-112$ \\
Body Mass Index $\left(\mathrm{kg} / \mathrm{m}^{2}\right)$ & $27.42(5.37)$ & 27.8 & $14.81-35.7$ \\
Total Cholesterol & $210.82(48.45)$ & 211 & $146-347$ \\
Random Blood Glucose & $141.12(106.90)$ & 104 & $83-426$ \\
\hline
\end{tabular}


Table 2 Variable Cardiovascular Risk of Jakarta Cardiovascular Score and European Relative Risk Score

\begin{tabular}{|c|c|c|c|}
\hline \multirow{3}{*}{ Variable } & \multicolumn{3}{|c|}{ Cardiovascular Risk } \\
\hline & Low & Moderate & High \\
\hline & n (\%) & n (\%) & n (\%) \\
\hline \multicolumn{4}{|l|}{ Age (years) } \\
\hline $25-34$ & $2(11.8)$ & - & - \\
\hline $25-39$ & $2(11.8)$ & - & - \\
\hline $40-44$ & $3(17.6)$ & - & $1(5.9)$ \\
\hline $45-49$ & - & $4(23.5)$ & - \\
\hline $50-54$ & $1(5.9)$ & $3(17.6)$ & - \\
\hline $55-59$ & - & - & - \\
\hline $60-64$ & - & - & $1(5.9)$ \\
\hline \multicolumn{4}{|l|}{ Blood Pressure } \\
\hline Normal & $5(29.4)$ & $2(11.8)$ & - \\
\hline Normal-High & $2(11.8)$ & $3(17.6)$ & - \\
\hline Hypertension grade 1 & $1(5.9)$ & $1(5.9)$ & - \\
\hline Hypertension grade 2 & - & - & $1(5.9)$ \\
\hline Hypertension grade 3 & - & $1(5.9)$ & $1(5.9)$ \\
\hline \multicolumn{4}{|l|}{ Body Mass Index ${ }^{a}$} \\
\hline $13.79-25.99$ & $5(29.4)$ & $2(11.8)$ & - \\
\hline $26.00-29.99$ & $2(1.8)$ & $3(17.6)$ & - \\
\hline $30.00-35.58$ & $1(5.9)$ & $2(11.8)$ & $2(11.8)$ \\
\hline \multicolumn{4}{|l|}{ Smoking } \\
\hline Never & $8(47.1)$ & $6(35.3)$ & $2(11.8)$ \\
\hline Ex-smoker & - & $1(5.9)$ & - \\
\hline \multicolumn{4}{|l|}{ Diabetes Mellitus } \\
\hline Yes & - & $1(5.9)$ & $1(5.9)$ \\
\hline No & $8(47.1)$ & $6(35.3)$ & $1(5.9)$ \\
\hline \multicolumn{4}{|l|}{ Physical Activities } \\
\hline No. & - & - & - \\
\hline Low & - & - & - \\
\hline Medium & $8(47.1)$ & $7(41.2)$ & $3(11.7)$ \\
\hline High & - & - & \\
\hline
\end{tabular}

(47.1\%), moderate (41.2\%) and high (11.7\%), whereas the average relative risk score based on SCORE Relative Risk Chart was $1.88 \pm 0.93$.

\section{Discussion}

Death from cardiovascular disease often occurs due to pathological conditions in blood vessels in the form of atherosclerosis. Our study has shown that the proportion of the high risk of cardiovascular disease according to Jakarta Cardiovascular Scores in health cadres in Cilayung Village, Jatinangor Sub-district is $11.7 \%$. This result reflects that health cadres

Althea Medical Journal. 2019;6(2) 


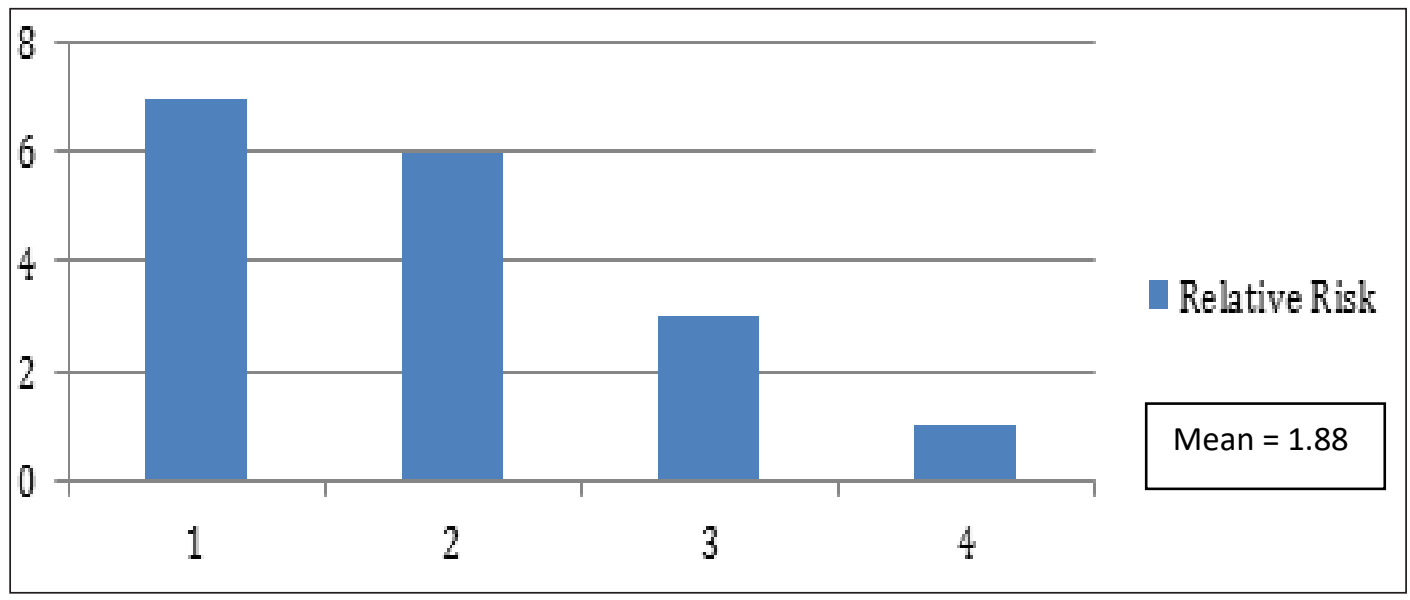

Figure 1 Total Relative Risk of Cardiovascular Disease based on SCORE Relative Risk Chart

in this region may have a risk of experiencing mortality due to cardiovascular disease in the next 10 years. 6 The highest relative risk in this study was age 60-64 (4 40.93$)$ and grade 3 hypertension $(3.5 \pm 0.71)$.

The aging process is a physiological thing that can cause atherosclerosis. From the results of the study, it appears that the highest frequency with high risk for age variables is in the age range 60-64 years. This study also showed that increased risk of cardiovascular disease in middle age $25 \%$ in $40-44$ years old at high risk and $100 \%$ in $45-49$ years old at moderate risk). It caused the proportion of the age group in this study was not equal. Another data about the prevalence of cardiovascular disease was increased with age that as increasing age will increase the process of atherosclerosis, causing heart and blood vessel disease. $^{8}$ The risk of heart and blood vessel disease increases at the age of 55 years and over for men and over 65 years for women. ${ }^{9}$ Based on the results of Basic Health Research (Riskesdas 2013), the highest prevalence of coronary heart disease occurred in the age range 65-74 years. ${ }^{2}$

Blood pressure is a modifiable risk factor for heart and blood vessel disease. If blood pressure exceeds more than normal values, it is categorized as hypertension. The risk factor of hypertension are lifestyle changes such as being overweight, excess salt consumption, and excessive alcohol consumption. ${ }^{9}$ With proper intervention, blood pressure can be controlled and maintain in normal conditions. Based on the results of this study, it can be seen that high risk is found in stage 3 hypertension groups. Hypertension is a silent factor and a major factor in heart and blood vessel disease. Increased blood pressure will increase the risk of heart and blood vessel disease. Risk management of heart and blood vessel disease needs to be done to reduce the prevalence of heart and blood vessel disease.

Obesity is also a risk factor that makes workers more at risk of suffering from heart and blood vessel disease. ${ }^{9}$ This study showed that the body mass index group of 30.0035.58 was $40 \%$ at high risk of cardiovascular disease. Excess weight is associated with type II diabetes and the causes of death in patients with Diabetes Mellitus are mostly caused by coronary heart disease and stroke. ${ }^{10,11}$ Therefore, management to reduce body weight in cadre becomes a priority in primary prevention.

Unhealthy lifestyles such as smoking and lack of physical activity can accelerate the occurrence of atherosclerosis. Nicotine substances in cigarettes cause the production of catecholamines which makes vessels undergo vasoconstriction, increase heart rate, and increase oxygen use. Cigarette smoke contains CO that can damage blood vessels. When CO enters the body, it will bind to hemoglobin in red blood cells, and causes red blood cells to carry less oxygen because the CO is transported instead of oxygen. Due to the lack of oxygen, the body will compensate by shrinking the blood vessels. If this condition persists, the blood vessels will be damaged and later on, it progresses into atherosclerosis which is the initial stage of heart and blood vessel disease. ${ }^{5}$ The results of the study found 
that high risk is experienced by the group who never smoked. This is because the subjects of this study were all women, so the number of the smoker was only 1 person.

People who had regular exercise or heavy physical activity have a lower risk of hypertension and coronary artery disease. ${ }^{5}$ Another study showed that only heavy physical activity associated with a reduced risk of premature coronary heart disease. ${ }^{12}$ Physical activity is body movement resulting from musculoskeletal contractions, which increases energy and improves health, encompasses activities outside of routine work such as light exercise, doing work household, going up and down the stairs either at the office or home at least 30 minutes every day. From the results of this study, all cadres had moderate physical activity with various risk of cardiovascular disease. Because of a similar level of physical activity in cadres, this study could not determine whether the level of physical activity influenced cardiovascular risk.

The limitation of this study is that all respondents are female. Our study cannot be compared to another study that also uses Jakarta Cardiovascular Score, showing that male has a greater score. ${ }^{5}$ The number of respondents in our study is also limited.

In conclusion, although most of the health cadres in Cilayung Village have a low risk of cardiovascular disease, lifetime risk to cardiovascular disease is increasing. Prevention and management programs for risk factors still need to be done in health cadres. For further study, it needs to assess awareness of health cadres to their health profile to prevent cardiovascular disease.

\section{References}

1. Ponikowski P, Voors AA, Anker SD, Bueno H, Cleland JG, Coats AJ, et al. 2016 ESC Guidelines for the diagnosis and treatment of acute and chronic heart failure: The Task Force for the diagnosis and treatment of acute and chronic heart failure of the European Society of Cardiology (ESC). Developed with the special contribution of the Heart Failure Association (HFA) of the ESC. Eur J Heart Fail. 2016;18(8):891-975.

2. Kementrian Kesehatan Republik Indonesia. Riset Kesehatan Dasar (Riskesdas). Jakarta: Kemenkes RI; 2013.

3. Jones CA, Ross L, Surani N, Dharamshi N, Karmali K. Framingham ten-year general cardiovascular disease risk: agreement between BMI-based and cholesterol-based estimates in a South Asian convenience sample. PloS one. 2015;10(3):e0119183.

4. World Health Organization. Prevention of cardiovascular disease: Guidelines for assessment and management of cardiovascular risk. Geneva: WHO Press; 2007.

5. Kusmana D. The influence of smoking cessation, regular physical exercise and/ or physical activity on survival: a 13 years cohort study of the Indonesian population in Jakarta. Med J Indones. 2002;11(4):23041.

6. Sofiatin Y, Roesli R. Kesiapan masyarakat dalam melaksanakan dan memanfaatkan Posyandu Penyakit Tidak Menular di Desa Cilayung dan Cipacing, Kecamatan Jatinangor. GMHC. 2017;5(2):123-31.

7. Piepoli MF, Hoes AW, Agewall S, Albus C, Brotons C, Catapano AL, et al. 2016 European Guidelines on cardiovascular disease prevention in clinical practice: The Sixth Joint Task Force of the European Society of Cardiology and Other Societies on Cardiovascular Disease Prevention in Clinical Practice (constituted by representatives of 10 societies and by invited experts) Developed with the special contribution of the European Association for Cardiovascular Prevention \& Rehabilitation (EACPR). Eur Heart J. 2016;37(29):2315-81.

8. Mozaffarian D, Benjamin EJ, Go AS, Arnett DK, Blaha MJ, Cushman M, et al. Executive summary: heart disease and stroke statistics-2015 update: a report from the American Heart Association. Circulation. 2015;131(4):434-41.

9. Lenfant C, Chobanian AV, Jones DW, Roccella EJ. Seventh report of the Joint National Committee on the prevention, detection, evaluation, and treatment of high blood pressure (JNC 7): resetting the hypertension sails. Circulation. 2003;107(24):2993-4.

10. Lam DW, LeRoith D. The worldwide diabetes epidemic. Curr Opin Endocrinol Diabetes Obes. 2012;19(2):93-6.

11. Nguyen NT, Nguyen XM, Lane J, Wang P. Relationship between obesity and diabetes in a US adult population: findings from the National Health and Nutrition Examination Survey, 1999-2006. Obes Surg. 2011;21(3):351-5.

12. Carnethon MR. Physical activity and cardiovascular disease: how much is enough? Am J Lifestyle Med. 2009;3(1_ suppl):44S-9S. 